\title{
Endoscope-assisted External Approach for Lateral Lesions in Frontal Sinus
}

\author{
Raghunath Shanbag, Vijay Bidkar, Ashok Naik, Roshan Jalisatgi
}

\begin{abstract}
Background: Lesions of the frontal sinus (FS) are always a surgical challenge. Conventional endonasal endoscopic techniques do not provide complete access inside the FS. This is especially true with laterally placed lesions like mucocele or post-traumatic cerebrospinal fluid (CSF) leak from FS. Standard procedures like osteoplastic flap and endoscopic modified Lothrop are not feasible for these smaller unilateral lesions with normally functioning contralateral sinus.
\end{abstract}

Study design: Retrospective case study of laterally placed posterior table CSF leak and frontal mucocele were evaluated for their clinical presentation, radiological, operative findings and follow-up.

Conclusion: Complete external approaches to the lateral lesion of FS are associated with high morbidity. Ability of the endoscopes to visualize lateral and posterior extents of the FS directly through the brow incision helps in complete repair/ excision of these lesions without any difficulty.

Keywords: Frontal sinus, Cerebrospinal fluid leak, Mucocele, Brow incision.

How to cite this article: Shanbag R, Bidkar V, NaikA, Jalisatgi R. Endoscope-assisted External Approach for Lateral Lesions in Frontal Sinus. Clin Rhinol An Int J 2013;6(2):72-76.

Source of support: Nil

Conflict of interest: None declared

\section{INTRODUCTION}

Surgery of the frontal recess (FR) and frontal sinus (FS) remains a challenge due to complex and variable anatomy. ${ }^{1}$ Incomplete and unacceptable intervention of the FS is thereby unforgivable. Selection of an appropriate approach depending upon the nature and site of the pathology is of utmost importance. Chronic rhinosinusitis (CRS) remains the most common condition affecting the FS except for few other uncommon conditions. Post-traumatic cerebrospinal fluid (CSF) leak and mucocele of FS can affect the sinus anywhere away from FR. Over the years approaches to the FS are evolving from radical to more functional by the use of nasal endoscopes. The use of endoscope has allowed better visualization and hence improved success rates, reduced morbidity. ${ }^{2}$ Most of the lesions in ethmoids and sphenoid can be repaired endoscopically, but same is not true for lesions of FS. ${ }^{3}$

Before the advent of endoscopic surgical procedures, external techniques like frontoethmoidectomy, osteoplastic flap with obliteration of FS were used to treat lesions of FS. Endoscopic sinus surgery has evolved as minimally invasive procedure to treat the diseases of the FS. But, this requires adequate experience and skill because of use of angled scopes and instrument in narrow recess. Not all the pathologies of FS can be approached satisfactorily by endonasal approach. This is especially true when they are large and located away from FR. Advanced procedure, such as endoscopic modified Lothrop procedure (EMLP) along with external approach should be reserved wherever, combined endonasal endoscopic and external technique fails to achieve desired outcomes.

In this study we describe a surgical technique of managing these lesions through a brow incision and a window in the anterior table of the FS for manipulation of endoscope and instruments through the same opening along with endonasal approach.

\section{MATERIALS AND METHODS}

A retrospective chart review was done on patients who underwent brow incision with frontal window and endoscope-assisted surgery for laterally placed lesions of FS between December, 2011 and January, 2013 at tertiary care teaching hospital. All the demographic data along with careful evaluation of preoperative symptoms, radiological findings and other associated comorbidities were assessed. Surgical records and postoperative radiographic findings were reviewed. Complications if any were recognized, treated and documented. Outcomes were assessed using subjective and objective measures in follow-up visits over 12 to 18 months.

\section{RESULTS}

\section{Surgical Technique}

The patients with pathology in FS whose lesions are inaccessible with endoscope by endonasal approach alone are considered for this approach. Preoperative evaluation of computed tomographic (CT) scan and MRI was done to ascertain suitability on individual basis. We included cases of post-traumatic CSF leak from posterior table of FS with distorted FR as a result of neo-osteogenesis secondary to previous trauma (Fig. 1) and laterally placed mucocele (Figs 2A and B).

A mini brow incision is made lateral to supraorbital foramen (Fig. 3). Periosteum is incised and underlying bone is exposed. In case of CSF leak from posterior table of FS, a 


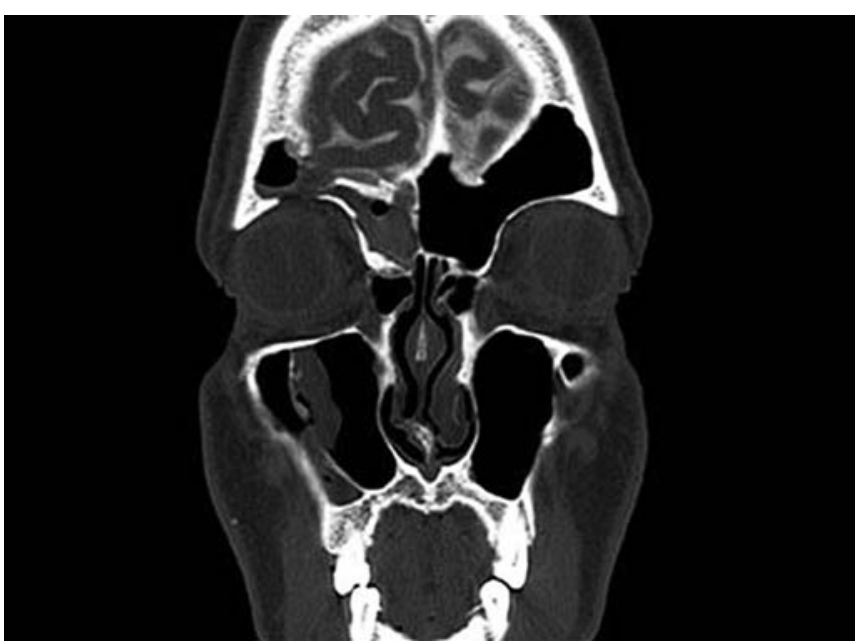

Fig. 1: Contrast-enhanced coronal CT scan of paranasal sinus showing laterally placed fracture in the posterior table of frontal sinus with CSF leak
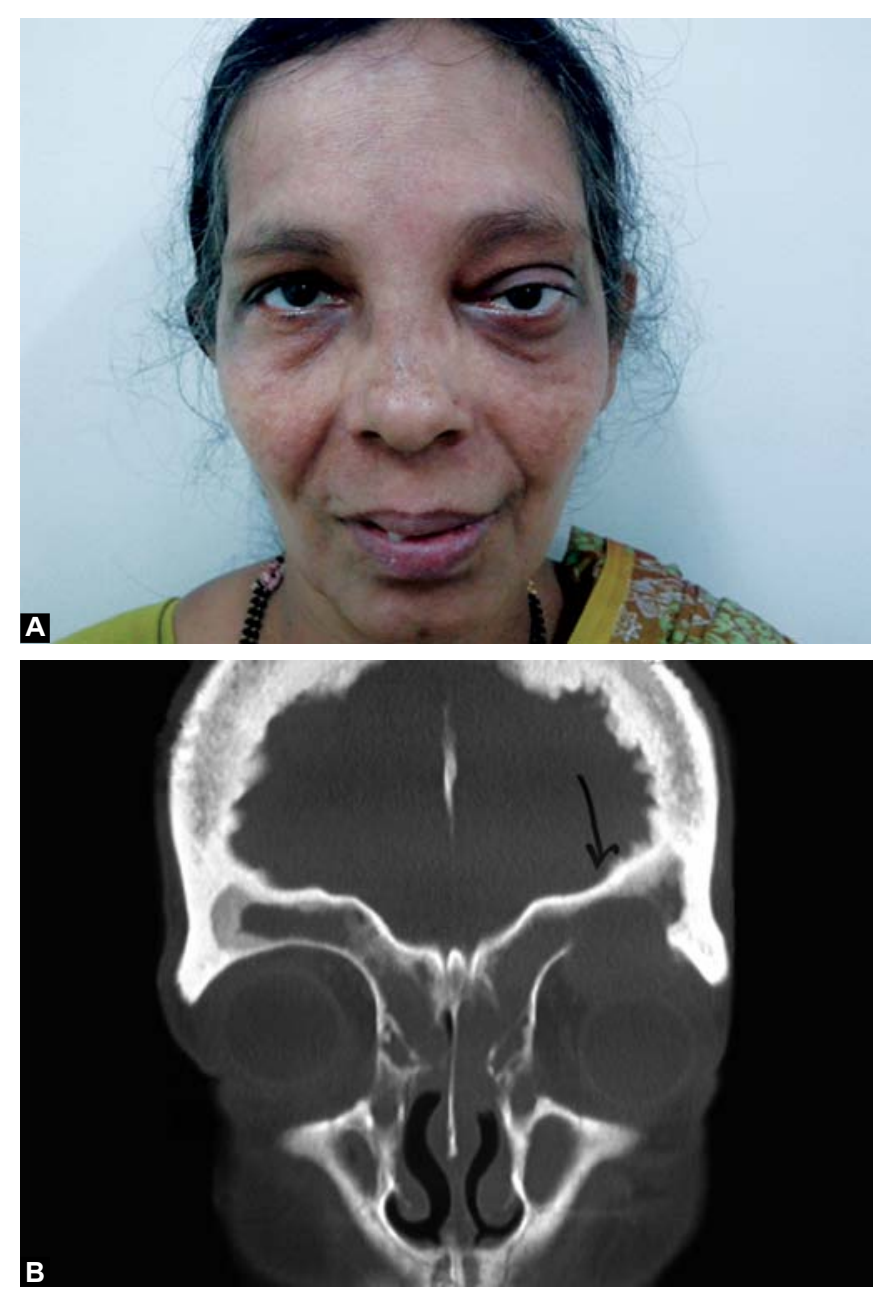

Figs 2A and B: (A) Left eyeball displaced inferiorly and laterally, (B) Preoperative CT coronal cut showing laterally placed mucocele (black arrow)

bony window is made with $4 \mathrm{~mm}$ cutting burr in the anterior wall of FS which is enlarged adequately as per requirement (maximum up to $10 \mathrm{~mm}$ ). Site of leak is evaluated with the help of endoscope. Rest of the mucosa of the sinus is

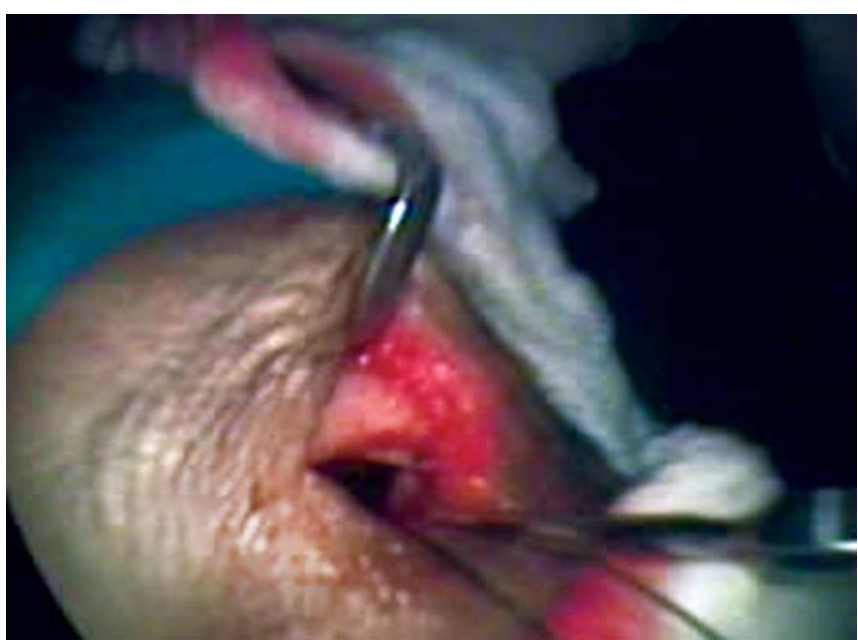

Fig. 3: Mini brow incision and window in the anterior frontal wall

stripped off carefully. We used inlay technique of grafting using fascia lata. Obliteration of rest of sinus was done in all the cases using abdominal fat.

In cases of laterally placed mucocele, the floor of FS was already found to be eroded due to expansile nature of the disease. The endoscope inserted through the brow incision enabled an accurate dissection and complete excision of the mucocele. Endonasal endoscopic ethmoidectomy and widening of FR is done to maintain postoperative drainage.

\section{Patient Characteristics}

Six patients, three cases of delayed post-traumatic CSF leak from posterior wall of FS and another three cases of lateral mucocele of FS were included in this study. Informed written consent was taken from all the patients. Approval from institutional ethics committee was sought. All the patients underwent external approach aided with endoscope as stated above. Average age of the patient presenting with CSF leak was 58.5 years, while in case of mucocele it was 75.5 years. We observed male preponderance in both CSF leak and mucocele. Delay in presentation of CSF leak was found to be 2 months to 2 years while in patients of mucocele it ranged from 2 to 6 months. The CSF leak patients presented as spontaneous onset of clear watery nasal discharge. It was confirmed with biochemical tests. Patients with mucocele presented with gradual proptosis and recent onset diplopia.

CT scan of paranasal sinuses of all the three patients of CSF leak revealed distorted FR due to neo-osteogenesis secondary to trauma involving FR. One of the patients who presented with behavioral changes had associated pneumocephalus.

Among the patients of mucocele one patient who had undergone endonasal endoscopic marsupialization of mucocele showed reappearance of the lesion on follow-up CT scan (Fig. 4) within 7 days. She then underwent combined 


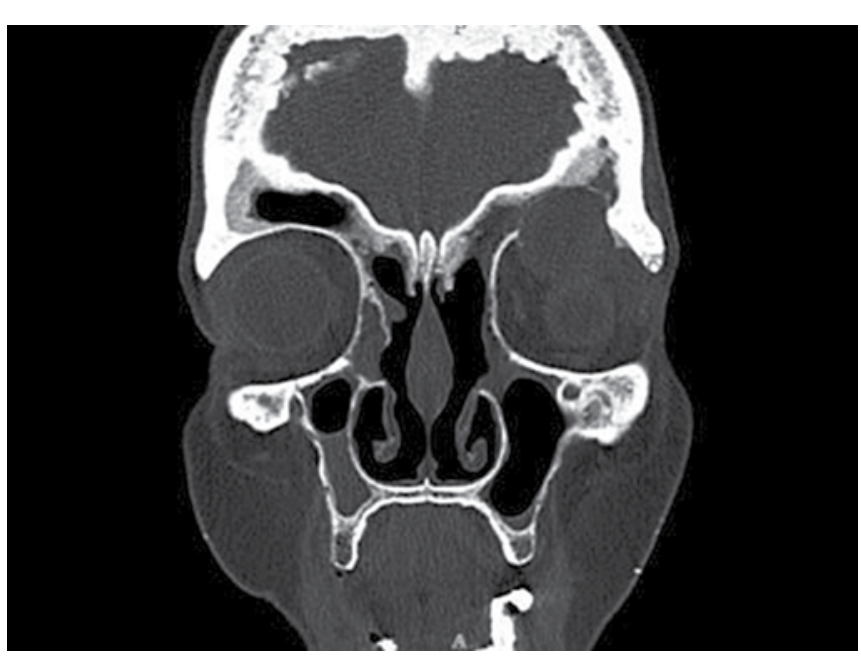

Fig. 4: Coronal CT scan showing reappearance of mucocele

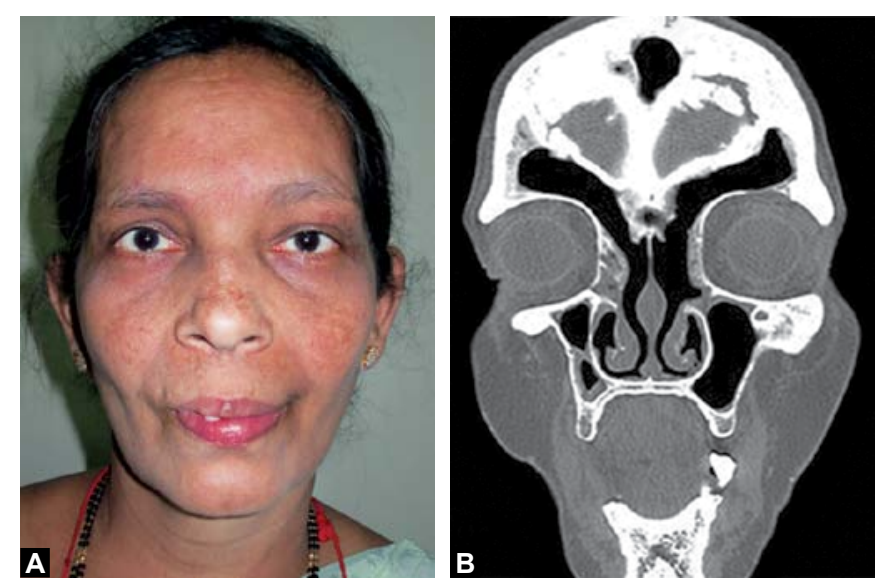

Figs 5A and B: (A) Clinical photograph after 6 months,

(B) Coronal CT showing complete excision of mucocele

endonasal and endoscope-assisted external excision of frontal mucocele. All the patients were followed up over 12 to 18 months. None had recurrence of CSF leak or mucocele on clinical and radiological evaluation (Figs 5A and B).

\section{Outcomes}

Of the six patients who underwent endonasal and endoscopeassisted external excision/repair through mini brow incision and FS bony window, one had transient supraorbital hypoesthesia for short duration which later recovered completely. The patient with pneumocephalus was observed with serial radiographs of skull lateral view. By the end of first week air inside the cranial cavity was significantly absorbed.

One of the mucocele case who presented with diplopia, improved in immediate postoperative period.

We did not found necessity to reconstruct anterior frontal table or roof of orbit, as the maximum size of defect was lesser than $10 \mathrm{~mm}$.

\section{DISCUSSION}

The lateral lesions of FS are always a surgical challenge and have been discussed intensely. Anatomical location of FS and large variation of drainage pathway makes FS unique. The outflow tract is surrounded by important structures like lamina papyracea laterally and thin lateral lamella of ethmoids labyrinth medially.

The external approach to the FS by Lynch-Howarth frontoethmoidectomy removes frontonasal process leading to medialization of the orbital contents. Hence, it is associated with higher recurrence rate as a result of obstruction of nasofrontal outflow tract. Consequently this approach is rarely practiced now. ${ }^{4}$ Recent improvement in the knowledge of sinus anatomy has helped approaching the FR and FS by endonasal route. Various endonasal procedures ranging from type I to III are described under FULDA concept. Hosemmann et $\mathrm{al}^{5,6}$ demonstrated the maximum average diameter possibly created by type IIa, was $5.6 \mathrm{~mm}$. Therefore, these complete endoscopic techniques involving removal of cells in the recess for widening of FR gives a limited access inside the FS. Reaching the lateral and superior edge of the lesion inside FS through above said procedures gives very narrow access with potential risk of damage to the important structures within the boundaries of the FR.

We have considered two heterogeneous conditions, affecting the lateral confines of FS. Both of these lesions

\begin{tabular}{|c|c|c|c|c|c|c|}
\hline Lesion & Age & Sex & Clinical presentation & Duration & $\begin{array}{l}\text { Side of } \\
\text { the lesion }\end{array}$ & CT findings \\
\hline Mucocele & 55 & $\mathrm{~F}$ & $\mathrm{PP}$ & 5 months & Left & CRS, erosion of floor of FS, mucocele \\
\hline Mucocele & 56 & M & PP, Diplopia & $\begin{array}{l}3 \text { months } \\
1 \text { week }\end{array}$ & Left & CRS, erosion of floor of FS, mucocele \\
\hline Mucocele & 40 & M & Supraorbital swelling & 6 months & Right & Erosion of floor of FS, mucocele \\
\hline CSF leak & 45 & M & $\begin{array}{l}2 \text { months postinjury } \\
\text { watery rhinorrhea }\end{array}$ & 1 week & Right & Neo-osteogenesis of FR, CSF leak posterior table FS \\
\hline CSF leak & 32 & M & $\begin{array}{l}2 \text { years postinjury } \\
\text { watery rhinorrhea }\end{array}$ & 1 week & Left & $\begin{array}{l}\text { Neo-osteogenesis of FR, CSF leak posterior table FS, } \\
\text { pneumocephalus }\end{array}$ \\
\hline CSF leak & 40 & $M$ & $\begin{array}{l}1 \text { year postinjury } \\
\text { watery rhinorrhea }\end{array}$ & 1 month & Right & $\begin{array}{l}\text { Frontal encephalocele, Neo-osteogenesis of FR, CSF } \\
\text { leak posterior table FS }\end{array}$ \\
\hline
\end{tabular}

PP: Proptosis, CRS: Chronic rhinosinusitis, FR: Frontal recess, FS: Frontal sinus 
are difficult to reach with routine endonasal endoscopic approach alone. A post-traumatic CSF leak and mucocele of FS located laterally in the FS are commonly encountered in otolaryngology practice.

The post-traumatic delayed CSF leaks sometimes are associated with distorted FR as a result of neo-osteogenesis of FR along the fracture lines. Opening and postoperative maintenance of such a FR even with advanced endonasal technique like EMLP becomes technically difficult. Nevertheless the risk of restenosis in such a FR even after EMLP cannot be underestimated. Though EMLP gives good working space of up to $1.5 \mathrm{~cm}$ it was deferred in both the conditions in this study as the contralateral sinus was healthy and unaffected, while remainder of the ipsilateral sinus mucosa was normal in all the patients.

Osteoplastic flap has served as definitive external approach for many of these lesions in the FS which cannot be approached by endonasal route. ${ }^{7}$ It provides wide exposure for complete removal of large neoplasms or clearance of refractory infective pathologies in the FS. But, they are associated with long-term comorbidities and complications such as loss of frontal contour, delayed formation of mucocele up to 10 to $30 \%$ of cases as reported by Kamowitz et al. ${ }^{8}$

We believe that unilateral smaller pathology like CSF leak or mucocele does not warrant morbid procedures as described above. Instead a combined external and endoscopic approach can provide greater access with lesser morbidity.

The technique of brow incision and FS bony window gives direct approach to the site of lesion through the incision. The risk of injury to supraorbital neurovascular bundle can be reduced by placing the incision lateral to supraorbital foramen. In our series only one patient had transient numbness which improved without sequele. Large incision medial to supraorbital foramen and inadvertent traction of skin flap and wide periosteum elevation are associated with injury to trochlea, which can result in postoperative diplopia as a result of superior oblique muscle palsy. ${ }^{9}$ As all the cases in this study had lesions in the lateral confines, medial incision was not necessary.

The opening in the bony anterior wall of FS can be widened adequately enough to accommodate endoscope and instrument simultaneously. ${ }^{10-12}$ The CSF leak from posterior table of the FS located lateral to medial orbital wall and extending into supraorbital cell is difficult to access endoscopically. ${ }^{13}$ Even with endoscopic Draf IIa getting to the upper edge of the leak, and drilling of surrounding bone for multilayered closure using fascia becomes difficult. An adjunctive external approach with use of endoscope through the brow incision and window in frontal bone is helpful for better surgical access to achieve secure CSF leak closure by underlay technique.

Mucocele affecting FS accounts for $89 \%$ of the overall sinuses. ${ }^{14}$ These laterally expanding expansile lesions causes gradual erosion of the floor of FS and occupy orbital space by pushing its contents inferiorly. Such a lesion with the erosion of orbital roof is difficult to access through endonasal approach with the use of endoscope even by Draf IIa. Therefore when an exclusive endonasal approach is not possible, external and endonasal approach may be combined. Endoscope used through the brow incision allows meticulous dissection and elevation of the mucocele wall from bare periorbita.

We acknowledge the small sample size of this study. Patients who underwent the specified technique described here are selected after careful evaluation which is vital for successful outcomes.

\section{CONCLUSION}

The lateral lesions of FS warrant more than a pure endonasal endoscopic procedure. A pure external approach with its inherent drawbacks can be avoided by judicious use of nasal endoscope through a mini incision on the eyebrow.

Such a combined endonasal and mini-external approach using endoscope is safe and effective for tackling lateral lesions of FS and CSF leaks from posterior table of FS.

The use of nasal endoscope through a mini brow incision helps facilitate identification, dissection and closure of above said lesions in lateral confines of FS. We believe that the risk of injury to orbital and intracranial structures is significantly less in combined external and endonasal technique.

\section{REFERENCES}

1. Wormald PJ. Surgery of the frontal recess and frontal sinus. Rhinology 2005 Jun;43(2):82-85.

2. Hegazy HM, Carrau RL, Snyderman CH, Kassam A, Zweig J. Transnasal endoscopic repair of cerebrospinal fluid rhinorrhoea: a meta-analysis. Laryngoscope $2000 \mathrm{Jul} ; 110(7): 1166-1172$.

3. Locatelli D, Ramappa F, Acchiardi I, Bignami M, De Bernardi F, Castelnuovo P. Endoscopic endonasal approaches for cerebrospinal fluid leaks: nine year experience. Neurosurgery 2006 Apr;58(4 Suppl 2):246-255.

4. Draf W, Weber R, Keerl R, Constantinidis J. Aspekte zur stirnhoehlenchirurgie. Teil I: Die endonasale stirnhoehlendrainage bei entzuendlichen erkrankungen der nasennebenhoehlen. HNO 1995;43:352-357.

5. Hosemann W, Kuehnel T, Held P, Wagner W, Felderhoff A. Endonasal frontal sinusotomy in surgical management of chronic rhinosinusitis: a critical evaluation. Am J Rhinol 1997 Jan-Feb;11(1):1-9.

6. Hosemann W, Gross R, Goede U, Kuehnel T. Clinical anatomy of nasal process of frontal bone (spina nasalis interna). Otolaryngol Head Neck Surg 2001 Jul;125(1):60-65. 
7. Weber R, Draf W, Keerl R, Kahle G. Schinzel S, Thomas $\mathrm{S}$, Lawson W. Osteoplastic frontal sinus surgery with fat obliteration: technique and long- term results using magnetic resonance imaging in 82 patients. Laryngoscope 2000 Jun;110(6):1037-1044.

8. Kamowitz SJ, Batra PS, Citardi MJ. Comprehensive management of failed frontal sinus obliteration. Am J Rhinol 2008 May-Jun;22(3):263-265.

9. Bartley J, Eaglton N, Rosser P, Al-Ali S. Superior oblique muscle palsy after frontal sinus mini-trephine. Am J Otolaryngol 2012 Jan-Feb;33(1):181-183.

10. Batra PS, Citradi MJ, Lanza DC. Combined endoscopic trephination and endoscopic frontal sinusotomy for management of complex frontal sinus pathology. Am J Rhinol 2005 SepOct;19(5):435-441.

11. Bent JP, Spears RA, Kuhn FA, Stewart SM. Combined endoscopic intranasal and external frontal sinusotomy. Am J Rhinol 1997 Sep-Oct;11(5):349-354.

12. Benoit CM, Duncavage JA. Combined external and endoscopic frontal sinusotomy with stent placement: a retrospective review. Laryngoscope 2001 Jul;111(7):1246-1249.

13. Purkey MT, Woodwarth BA, Hahn S, Palmer JN, Chiu AG. Endoscopic repair of supraorbital ethmoids cerebrospinal fluid leaks. ORL J Otorhinolaryngol Relat Spec 2009;71(2):93-98.
14. Lund VJ. Anatomical consideration in the aetiology of frontoethmoidal mucoceles. Rhinology 1987 Jun;25(2):83-88.

\section{ABOUT THE AUTHORS}

\section{Raghunath Shanbag}

Professor, Department of Otorhinolaryngology, SDM College of Medical Sciences and Hospital, Dharwad, Karnataka, India

\section{Vijay Bidkar (Corresponding Author)}

Assistant Professor, Department of Otorhinolaryngology, SDM College of Medical Sciences and Hospital, Dharwad-580009 Karnataka, India, Phone: 08362477743, Fax: +91-8362460090 e-mail: vijay20dr@gmail.com

\section{Ashok Naik}

Professor and Head, Department of Otorhinolaryngology, SDM College of Medical Sciences and Hospital, Dharwad, Karnataka, India

\section{Roshan Jalisatgi}

Assistant Professor, Department of Otorhinolaryngology, SDM College of Medical Sciences and Hospital, Dharwad, Karnataka, India 